\title{
Coated and uncoated cellophane as materials for microplates and open-channel microfluidics devices
}

\section{Citation}

Hamedi, Mahiar M., Baris Ünal, Emily Kerr, Ana C. Glavan, M. Teresa Fernandez-Abedul, and George M. Whitesides. 2016. Coated and Uncoated Cellophane as Materials for Microplates and Open-Channel Microfluidics Devices. Lab Chip 16, no. 20: 3885-3897. doi:10.1039/c6lc00975a.

\section{Published Version}

10.1039/c6lc00975a

\section{Permanent link}

http://nrs.harvard.edu/urn-3:HUL.InstRepos:30354002

\section{Terms of Use}

This article was downloaded from Harvard University's DASH repository, and is made available under the terms and conditions applicable to Open Access Policy Articles, as set forth at http:// nrs.harvard.edu/urn-3:HUL.InstRepos:dash.current.terms-of-use\#OAP

\section{Share Your Story}

The Harvard community has made this article openly available.

Please share how this access benefits you. Submit a story.

\section{Accessibility}




\title{
Coated and Uncoated Cellophane as Materials for Microplates and Open-channel Microfluidics Devices
}

\author{
Mahiar M. Hamedi ${ }^{1+}$, Barış Ünal ${ }^{1+}$, Emily Kerr ${ }^{1,2}$, Ana C. Glavan ${ }^{1}$, M. Teresa \\ Fernandez-Abedul ${ }^{3}$, George M. Whitesides ${ }^{1,4^{*}}$
}

${ }^{1}$ Department of Chemistry and Chemical Biology, Harvard University, Cambridge MA

${ }^{2}$ Centre for Chemistry and Biotechnology, School of Life and Environmental Sciences, Faculty of Science, Engineering and Built Environment, Deakin University, Geelong, Victoria, 3220, Australia

${ }^{3}$ Departamento de Química Física y Analítica, Universidad de Oviedo, Julián Clavería 8, 33006 Oviedo, Asturias, Spain

${ }^{4}$ Wyss Institute for Biologically Inspired Engineering, Harvard University, Cambridge, MA

(+) These authors contributed equally to this work

(*) Author to whom correspondence should be addressed:

gwhitesides@gmwgroup.harvard.edu 


\section{Abstract}

This communication describes the use of uncoated cellophane (regenerated cellulose films) for the fabrication of microplates, and the use of coated cellophane for the fabrication of open-channel microfluidic devices. The microplates based on uncoated cellophane are particularly interesting for applications that require high transparency in the ultraviolet (UV) regime, and offer a low-cost alternative to expensive quartzwell plates. Uncoated cellophane is also resistant to damage by various solvents. The microfluidic devices, based on coated cellophane, can have features with dimensions as small as $500 \mu \mathrm{m}$, and complex, non-planar geometries. Electrodes can be printed on the surface of the coated cellophane, and embedded in microfluidic devices, to develop resistive heaters and electroanalytical devices for flow injection analysis, and continuous flow electrochemiluminescence (ECL) applications. These open-channel devices are appropriate for applications where optical transparency (especially in the visible regime), resistance to damage by water, biocompatibility and biodegradability are important. Cellophane microfluidic systems complement existing cellulose-based paper microfluidic systems, and provide an alternative to other materials used in microfluidics, such as synthetic polymers or glass. Cellulose films are plausible materials for uses in integrated microfluidic systems for diagnostics, analyses, cellculture, and MEMS.

\section{Introduction}

Cellulose-based paper has emerged as a useful material for the fabrication of microfluidic devices, especially in the area of diagnostics. ${ }^{1-5}$ Paper has three characteristics that differentiate it from glass, elastomers (e.g. PDMS), and synthetic polymers (e.g. polycarbonate) as a material for microfluidics: i) It is porous and 
hydrophilic: Porosity allows for immobilization of biomolecules inside the pores of paper, and hydrophilicity allows spontaneous wicking of water which is useful for microfluidic applications. ii) Printing of hydrophobic regions into paper (e.g. using wax printing), and stacking of paper sheets, enables the fabrication of threedimensional paper microfluidic devices. ${ }^{6}$ Printing of electronic inks, on the surface of, or inside, paper allows the fabrication of electroanalytical paper devices. ${ }^{3,7}$ iii) It is safe during handling and disposal, (e.g. paper does not fracture and produce "sharps", and it can be incinerated). Despite its useful characteristics, some physical properties of paper fabricated from cellulose fibers limit its use in applications in which wicking flow is not desirable; These limitations include transport of complex fluids that contain suspended particles, and the development of multiphase systems involving drops or bubbles. Paper also scatters light and is not transparent. Optical opacity limits its use for microfluidic applications (e.g. fluorescence, electrochemiluminescence ECL, or absorption spectroscopy) that require transmission and/or emission of light.

Here we extend the use of cellulose-based microfluidic systems by demonstrating transparent, open-channel devices based on cellophane. "Cellophane" is the trademark name for cellulose films that are manufactured by regenerating cellulose from cellulose xanthate (viscose). ${ }^{8,9}$ Today cellulose films are mainly used as an environmentally-friendly packaging material. ${ }^{10,11}$ Cellophane has properties that are complementary to those of paper (see Table 1) as a substrate for microfluidic devices: i) It is readily available and inexpensive (less than $1 \mathrm{USD} / \mathrm{m}^{2}$, or 0.05 cent $/ 5$ $\mathrm{cm}^{2}$ - the typical size of a paper microfluidic chip) in large quantities. ii) It is easily disposed of by incineration without producing sharps. iii) It is, in its unmodified form, biocompatible ${ }^{12}$ and biodegradable. ${ }^{13}$ iv) It does not dissolve in most organic solvents, 
or aqueous solutions ${ }^{14,15}$ (such as solutions commonly used in biochemistry and molecular biology applications, or biological fluids such as human blood, urine, or saliva). v) It is semi-permeable, and its permeability can be tuned to allow different molecular/weight cutoffs for use as dialysis membranes. vi) It has a printable surface (like paper) but with less surface roughness than paper. vii) It has excellent optical transparency — comparable to glass and most plastics — over the entire visible range, as well as in the UV range. ${ }^{16}$

Paper microfluidic systems $s^{4,17}$ are based on the spontaneous wicking of liquids (especially water and aqueous buffers) through the porous matrix of cellulose-based paper, often through a fluid path defined by hydrophobic wax barriers. ${ }^{18}$ Widely used analytical methodologies such as electrochemical monitoring of glucose, and lateral flow immunoassays were the first (and still largest volume) paper-based devices to enter large-scale fabrication (unless we count simple sensing paper strips). Our work, and that of others, ${ }^{1,2,4,19,20}$ has focused on paper microfluidics as an alternative technology for applications in medical diagnostics for resource-limited settings, environmental monitoring, food-safety testing, and molecular diagnostics. We have previously described pressure-driven flows in open-channel paper-based microfluidic systems. These microfluidic devices were fabricated using embossing or cutting (using a machine-driven knife) to shape channels in paper, silanization to make the paper hydrophobic; and plastic tape to seal the top of the channels. ${ }^{21,22}$ Renault et al. created hollow channels in the spacing between layers of paper, ${ }^{23,24}$ where waxprinted barriers confined the liquid in the channel. These hybrid systems successfully demonstrate the classical, diffusion-limited co-flows that are characteristic of openchannel microfluidic devices, ${ }^{25}$ but they still suffer from drawbacks, such as the use of synthetic polymers, and the lack of optical transparency across the device. Index- 
matching has been used to increase the transmission of light through paper in paper microfluidic systems for quantitative colorimetric point of care (POC) diagnostics, by wetting the paper with a liquid with an index of refraction similar to that of cellulose $^{26}$. Index-matching does not render paper fully transparent, and the liquids used for index matching fill the pores of paper, rendering capillary flows ineffective.

This paper describes microfluidic systems made from regenerated cellulose films (cellophane). Cellophane microfluidic devices add new capabilities to cellulosebased paper microfluidics. We show the fabrication of microplates by embossing 96well plate structures onto uncoated cellophane, and we also show the fabrication of open-channel microfluidic devices by embossing microstructures onto coated cellophane, followed by heat-sealing. The embossed microstructures have relatively small features (down to 500- $\mu$ m-wide channels) and complex non-planar geometries. We also show that electrodes can be printed on the surface of the coated cellophane and embedded into layered microfluidic systems, to develop resistive heaters and electroanalytical devices for analytical flow injection systems, and ECL applications.

\section{Materials and methods}

\section{Materials}

We used commercially available uncoated cellophane $\left(\mathrm{C}^{\mathrm{OH}}\right)$ with the commercial name "Cellophane P", cellophane with an approximately one micron thick coating of nitrocellulose $\left(\mathrm{C}^{\mathrm{NS}}\right)$ with the commercial name "Cellophane LMS", and cellophane with an approximately one micron thick coating of polyvinylidene chloride $\left(\mathrm{C}^{\mathrm{PVC}}\right)$ with the commercial name "Cellophane XS". The coatings allow different sheets of cellophane to be heat-sealed against each other, and also provide a barrier to prevent water from entering and swelling the cellophane (Innovia Films Ltd. ${ }^{27}$ kindly 
provided the cellophane materials used in this study.) We used $28-\mu \mathrm{m}$ and $35-\mu \mathrm{m}-$ thick uncoated cellophane, $30-\mu \mathrm{m}$-thick cellophane with a double-sided nitrocellulose coating, and 42- $\mu \mathrm{m}$-thick cellophane with a double-sided polyvinylidene chloride coating.

The silanes, 3,3,4,4,5,5,6,6,7,7,8,8,9,9,10,10,10 heptadecafluorodecyl trichlorosilane, $\mathrm{CF}_{3}\left(\mathrm{CF}_{2}\right)_{7} \mathrm{CH}_{2} \mathrm{CH}_{2} \mathrm{SiCl}_{3}\left(\mathrm{C}_{10}{ }^{\mathrm{F}}\right)$, and decyltrichlorosilane $\left(\mathrm{C}_{10}\right)$ were purchased from Gelest Inc. (Morrisville, PA).

Hexadecane, glycerol, ethylene glycol, ethanol, dimethyl sulfoxide (DMSO), N-Methyl-2-pyrrolidone (NMP), tetrahydrofuran (THF), methyl-2-pyrrolidone, dimethylformamide (DMF), L-proline, tris(2,2'-bipyridyl)ruthenium(II) chloride $\left(\mathrm{Ru}(\mathrm{bpy}){ }_{3}{ }^{2+}\right)$, sodium 4-(2-hydroxy-1-naphthalenylazo)-naphthalenesulfonate), fluorescein and Reactive Blue 2, adenine, bovine serum albumin (BSA), acetaminophen, and thiamine were purchased from Sigma-Aldrich. Food color was purchased from $\mathrm{McC}$ ormick. $\mathrm{Ag} / \mathrm{AgCl}$ ink was purchased from Ercon. All chemicals were used as received without further purification.

\section{Silanization}

The silanization reaction was conducted in a chamber with a volume of $0.01 \mathrm{~m}^{3}$ at a temperature of $95^{\circ} \mathrm{C}$. The organosilane was transferred into a glass vial under an inert gas atmosphere, and placed inside the chamber together with the samples. Each experiment required approximately $100 \mathrm{mg}$ of silane in $3 \mathrm{~mL}$ of anhydrous toluene. The organosilane was vaporized at $95^{\circ} \mathrm{C}$ under reduced pressure $(\sim 30 \mathrm{mbar}$, $0.03 \mathrm{~atm})$ and was allowed to react for 20 minutes.

\section{Contact angle measurements}


The contact angle measurements ( $\mathrm{n}=7$ for each contact angle) were performed by a contact angle goniometer (Ramé-Hart model 100, Ramé-Hart Instrument Co.) at room temperature $\left(20-25{ }^{\circ} \mathrm{C}\right)$ with $\sim 30 \%$ relative humidity.

\section{Testing solvent compatibility}

We tested the compatibility of uncoated cellophane $\left(\mathrm{C}^{\mathrm{OH}}\right)$, with the solvents: hexadecane, glycerol, ethylene glycol, ethanol, DMSO, NMP, THF, and NMP, DMF, by immersing the uncoated cellophane in each solvent for a period of 2 days. The cellophane sheets were then removed from the solvent and dried in an oven at $110{ }^{\circ} \mathrm{C}$, for $30 \mathrm{~min}$. We could not observe any apparent qualitative change in the mechanical or optical structures of the dry solvent-exposed cellophane from sheets that had not been exposed to any solvent. DMSO was the only solvent (beside water) that noticeably swelled the cellophane.

\section{Fabrication of uncoated cellophane microplates, and optical measurements}

Molds for 96-well plates were designed using Autodesk 3dsMax. The molds (one with a positive and one with a negative relief) were fabricated in polyurethane using a Connex500 3D Printer from Stratasys Ltd. We used 3D printing because it can rapidly prototype molds; these polyurethane molds, however, could only be used at room temperature to avoiding melting or deformation. Metallic molds would be more suitable alternatives for routine application, because they are more rigid during the embossing, and because they do not distort in heating. We stored uncoated cellophane $\left(\mathrm{C}^{\mathrm{OH}}\right)$ sheets in deionized water for at least two hours prior to embossing. This step was necessary to prevent the cellophane $\mathrm{C}^{\mathrm{OH}}$ from further swelling when a liquid was placed into the wells. Next, we compressed the cellophane $\mathrm{C}^{\mathrm{OH}}$ sheet 
between the molds to form the wells (using a pressure of around $1 \mathrm{psi}$ ), and suspended the embossed cellophane sheet on a standard frame for 96-well plates. We filled the wells with $10 \mu \mathrm{L}$ of solution using a micropipette, and carried out the optical measurement using a standard 96-well plate reader (SpectraMax M2e Multi-Mode Microplate reader). UV-Visible Spectra were collected for analytes $(0.01 \mu \mathrm{g} / \mathrm{mL}$ in deionized water) in 1-cm path-length quartz cells to determine the absorption maxima.

\section{Fabrication and operation of the microfluidic devices}

Molds for microfluidic devices were designed using SolidWorks and fabricated by Proto Labs Inc. in aluminum, using computerized numerical control machines (CNC), and sandblasted for a smooth finish (see Figures S1, S2). We used aluminum molds because small microfluidic features can be shaped into this metal, and because it can be heated to $120 \mathrm{C}^{\circ}$ for embossing and heat-sealing.

We used coated cellophane $\left(\mathrm{C}^{\mathrm{PVC}}\right.$, and $\left.\mathrm{C}^{\mathrm{NS}}\right)$ for fabrication of the devices, and stored the sheets in a vacuum desiccator chamber for at least one day prior to use. This step was necessary to remove the water, that is pre-absorbed from air in the cellophane so that the sheets would not shrink during the molding and sealing processes, due to drying of the pre-absorbed water. This step may also be done using a dry desiccator. In the fabrication process, the metallic molds were first heated to $\sim 120 \mathrm{C}^{\circ}$ in an oven. We compressed one dry cellophane $\left(\mathrm{C}^{\mathrm{PVC}}\right.$, or $\left.\mathrm{C}^{\mathrm{NS}}\right)$ sheet between two molds, using a pressure of 1-5 psi for the embossing, and then used a second dry cellophane $\left(\mathrm{C}^{\mathrm{PVC}}\right.$, or $\left.\mathrm{C}^{\mathrm{NS}}\right)$ sheet, and compressed this sheet against the embossed sheet at a higher pressure, around $10 \mathrm{psi}$, with a second set of molds. The final step seals the microfluidic channel by heat-sealing of the coatings. The embossing step 
took $10-30$ seconds while the heat sealing required $30-60$ seconds. We connected the microfluidic channels to silicone tubing (1/16", purchased from McMaster), using flangeless ferrules (Tefzel, Item\# EW-02007-54) affixed to the device with a thick transparent double-sided tape (VHB from 3M).

A two-channel syringe pump (Harvard PHD 2000) drove fluids from the inlets to the outlets of the open micro channels at different flow rates.

\section{Fabrication of the electrochemical devices and heaters}

We used a Laser cutter (VL-300, 50 Watt, Versa Laser) to cut shapes in an adhesive tape (polypropylene low-tack adhesive-backed film, 0.002" thick, purchased from McMaster-Carr). The adhesive tape served as a stencil mask by attaching it to a single sheet of cellophane. A carbon ink (Ercon inc.) was then applied using a clean-room swab through the stencil mask, to print the electrodes. The mask was removed, and the ink was allowed to dry at room temperature for 1 hour and then the cellophane sheets were stored in a desiccator for 1 day, to remove any excess solvent from the ink, and to dry the cellophane sheet (to prevent buckling during embossing). The cellophane sheets with the carbon print were used for making microfluidic devices. By placing the printed electrodes so that they faced the microfluidic channel, we could fabricate electrodes inside of the channel (Figure 3A). By placing the printed electrodes facing the outer part of the device, we could fabricate resistive heating elements (Figure 8).

\section{Flow injection electroanalysis}

We used phosphate-buffered saline (1xPBS, $\mathrm{pH} 7.0)$ as the carrier buffer, and different concentrations of potassium ferrocyanide as a redox probe, in 1xPBS. All 
solutions were pumped at $50-\mu \mathrm{L}$ per minute using two syringe pumps (Harvard PHD 2000), in such way that we only pumped using one syringe pump at a time (either the carrier buffer or the ferrocyanide). We recorded the current (at a potential of $+0.4 \mathrm{~V}$ vs. carbon ink) using three carbon electrodes (working-, counter-, and quasi-reference electrode). We used an Autolab potentiostat from Metrohm.

\section{Electrochemiluminescence (ECL)}

For ECL measurements, we stencil-printed an $\mathrm{Ag} / \mathrm{AgCl}$ quasi-reference electrode, instead of a carbon reference electrode, to achieve more accurate oxidation potentials. Next, we prepared $0.2 \mathrm{mM} \mathrm{Ru}(\mathrm{bpy})_{3}{ }^{2+}$ and standards of L-proline $(0.1$ to $1 \mu \mathrm{M})$ in 0.1 M phosphate buffer ( $\mathrm{pH} 7.5)$. We positioned the working electrode of the flow cell directly above a $4 \mathrm{~mm}^{2}$ Si photodiode (DET36A, Thorlabs), interfaced to the ADC164 module of the potentiostat using a BNC cable. We injected the Ru(bpy) ${ }_{3}{ }^{2+}$ ( $2 \mathrm{mM}$ ) and L-proline (using a range of concentrations) in the two inlets at a constant flow rate of $10 \mu \mathrm{L}$ per minute. We configured the potentiostat to apply 0.5 -second potential pulses at a potential of $1.25 \mathrm{~V} v s . \mathrm{Ag} / \mathrm{AgCl}$, with a 5-second delay time between measurements and recorded the light intensity. The ECL signal was calculated by integrating the area under the measured light intensity, using NOVA software. We varied the sample by manually changing the sample inlet between syringes pumps with different concentrations of L-proline.

\section{Results and Discussion}

\section{Surface wetting properties of uncoated, coated and silanized cellophane}

We examined (using measurements of apparent static contact angles, $\theta_{\text {app}}$ ) the wettability of cellophane with different modifications using a series of organic liquids 
spanning a wide range of surface tensions. The uncoated cellophane $\mathrm{C}^{\mathrm{OH}}$ used in these experiments was silanized with either a fluorinated or a non-fluorinated alkyl silane in the vapor phase, or was used as received (the pure, untreated cellophane and the cellophane coated with nitrocellulose). Figure 1A shows that silanization rendered the uncoated cellophane hydrophobic. The wettability of the alkyl-silanized cellophane and cellophane $\mathrm{C}^{\mathrm{NS}}$ were similar under our experimental conditions, while cellophane $\mathrm{C}^{\mathrm{PVC}}$ showed lower contact angles than $\mathrm{C}^{\mathrm{NS} \text {. }}$

Silanization with a fluoroalkyl silane afforded only a modest increase in contact angle for a given liquid. Since nitrocellulose and PVC-coated cellophane are commercially available, we used them in most of our investigations. Cellophane silanized with fluorinated alkylsilanes may, however, be useful in applications that require omniphobic surfaces. ${ }^{28}$

\section{UV-Visible transmission and absorption}

Cellophane is transparent across a remarkably wide wavelength window, compared to most plastics $^{29}$, and typical glasses. Figure 1B shows UV-Visible transmission spectra of cellophane sheets, in comparison with cellulose acetate, a commercial plastic cuvette (PMMA), and a quartz cuvette. The cellophane sheets are highly transparent in the visible regime, and also in the UV regime, with over $65 \%$ transmittance for uncoated cellophane $\mathrm{C}^{\mathrm{OH}}$, and $40 \%$ transmittance for coated cellophane $\mathrm{C}^{\mathrm{PVC}}$, at 250 nm.

\section{Microplates}

The high UV transparency of cellophane in the UV makes it a possible alternative to quartz cuvettes or quartz microplates for certain applications. The unmodified surface 
properties of uncoated cellophane, which is chemically similar to paper, may also provide a platform for cell-culture, or for analytical applications requiring immobilization of DNA or proteins on its surface..$^{30,31}$

We used polyurethane molds with patterns analogous to those of a 96-well plate to emboss wells into uncoated cellophane $\mathrm{C}^{\mathrm{OH}}$ (see Figure S3). Wells embossed in dry cellophane $\mathrm{C}^{\mathrm{OH}}$ buckled and deformed when we placed them in contact with water, since water swells uncoated cellophane. To prevent buckling of the wells, we pre-soaked the cellophane sheets in deionized water prior to embossing (see experimental). When the cellophane $\mathrm{C}^{\mathrm{OH}}$ is pre-soaked, the aqueous solutions in the wells cannot be absorbed by the cellophane, and the only transport and spread of liquids inside the cellophane is by diffusion (which is slow compared to the measurement times that we use for the absorption measurement).

We used embossed cellophane $\mathrm{C}^{\mathrm{OH}}$ 96-well plates to measure the UV absorption of four analytes: bovine serum albumin (BSA), adenine, acetaminophen, and thiamine (vitamin B1). These analytes were chosen because of their range of absorbance maxima within the UV region $\left(\lambda_{\max }\right.$ of $280,260,242$ and $238 \mathrm{~nm}$ respectively). This range allowed us to examine the suitability of cellophane $\mathrm{C}^{\mathrm{OH}}$ as an alternative material to quartz for UV absorption measurements across these wavelengths.

We measured a linear response range (see Figure 3B) for all four analytes with a cellophane 96-well plate, in which each well contained $10 \mu \mathrm{L}$ solutions of the analytes in deionized water. Table 2 summarizes analytical figures of merit, and limits of detection (LODs). The concentration range and LOD for adenine, was comparable to the concentrations that can be measured using instruments frequently used for determining concentrations of DNA/protein such as the NanoDrop ${ }^{\mathrm{TM}}$, which measures 
absorption through liquids without using a container that holds the liquid. The linear range for both acetaminophen and thiamine in the cellophane microplates is appropriate for analytical measurements in routine pharmaceutical and food-science settings $^{32,33}$, but not for high-sensitivity measurements.

Embossed cellophane $\mathrm{C}^{\mathrm{OH}}$ well plates have to be kept wet for the duration of the analysis (wells will distort and buckle upon drying), which may be a limiting factor in storage and shipping. For this reason, we also embossed microplates using dry sheets of coated cellophane $\left(\mathrm{C}^{\mathrm{PVC}}\right.$, and $\left.\mathrm{C}^{\mathrm{NS}}\right)$. Embossed wells in coated cellophane do not swell since the water in the wells cannot penetrate through the coating and into the cellophane. Due to the high liquid contact angles of aqueous solutions for coated cellophane $\left(\mathrm{C}^{\mathrm{PVC}}\right.$, and $\left.\mathrm{C}^{\mathrm{NS}}\right)$, the samples did not evenly coat the surface of the wells, which resulted in inconsistencies in the path-length of the samples. We, therefore, sealed the wells with tape (polyolefin films with silicone adhesive from VWR ${ }^{\circledR}$, used for PCR in well-plates) after having placed the liquid in the well, to enclose the liquids and ensure a more consistent path length. We designed the dimensions of the microplate molds so that $10 \mu \mathrm{L}$ of aqueous solution, which was added to each well using a pipette, would completely fill each well. The standard error from the coated cellophane $\mathrm{C}^{\mathrm{PVC}}$, and $\mathrm{C}^{\mathrm{NS}}$ microplates was notably higher for all four analytes than with cellophane $\mathrm{C}^{\mathrm{OH}}$ well plates (see table $\mathrm{S} 1$, in the SI); probably as a result of higher UV absorption by the coating and the tape. We think that microplates fabricated using coated cellophane $\left(\mathrm{C}^{\mathrm{PVC}}\right.$, and $\left.\mathrm{C}^{\mathrm{NS}}\right)$ may be more appropriate than those from $\mathrm{C}^{\mathrm{OH}}$ for applications that do not require UV transparency. Furthermore, they can be prepared and stored prior to use.

Fabrication of cellophane $\mathrm{C}^{\mathrm{NS}} / \mathrm{C}^{\mathrm{PVC}}$ microfluidic devices 
To further explore cellophane, and coated derivatives of it, as materials for microfluidic applications, we developed a method to fabricate open-channel cellophane microfluidic devices. Since pure cellophane swells in aqueous solutions and is not heat-sealable, we used coated cellophane $\left(\mathrm{C}^{\mathrm{PVC}}\right.$, and $\left.\mathrm{C}^{\mathrm{NS}}\right)$. The $\mathrm{NS}$ and PVC coatings allow different sheets of cellophane to be heat-sealed against one another, and also provided a barrier to prevent water from entering and swelling the cellophane.

The fabrication of the microfluidic devices required three steps (see Figure 3A): i) A dry, coated cellophane sheet was compressed between two metallic stamps kept at $\sim 120^{\circ} \mathrm{C}$, for $10 \mathrm{~s}$, to emboss the desired microfluidic features. The bottom mold is used for both heat-sealing and embossing, and it is therefore more practical to have this mold heated throughout the process. It should however be possible to also perform the embossing step by using molds at room temperature. ii) A second coated cellophane sheet, was placed against the embossed film. A heated metallic mold $\left(\sim 120^{\circ} \mathrm{C}\right)$ was then placed on top to heat-seal the two cellophane films, and to enclose the embossed channels. The heat causes the plastic coatings to melt and fuse together for sealing; cellophane is not a thermoplast. iii) Small holes were punched into the cellophane, either before or after sealing, for fluidic connections. We connected the inlets and outlet holes to standard flangeless ferrules using strong double-sided tape $\left(\mathrm{VHB}^{\circledR}\right.$ from $\left.3 \mathrm{M}^{\circledR}\right)$. Silicone tubing was used to drive fluids into the channels.

We used metallic stamps to form microfluidic structures, and to seal microfluidic channels. Metallic stamps can be readily manufactured with standard industrial techniques, such as $\mathrm{CNC}$ machining (used here), laser cutting and printing, or water-jet cutting. The resolution of the metallic stamps used to form features on 
embossing is the main factor limiting the size of the features used in the microfluidic devices. We have not established a true lower limit to this dimension.

To show the versatility of this technique, we designed and fabricated three cellophane microfluidic devices with different flow features: i) a "Y-junction device" (2A), ii) a "cross-junction device" (2B), and iii) a "T-junction device" (2C). The microfluidic device with a Y-junction had channels that were 1-mm wide and 250$\mu \mathrm{m}$-deep. The microfluidic device with a cross-junction, and the device with $\mathrm{T}$ junction, both had serpentine channels. Repeating C-shaped units can turn the fluid through $180^{\circ}$ to induce chaotic advection and passively enhance the mixing of the streams. ${ }^{34}$ The cross-junction device had a circular window intended for optical measurement. The aspect ratio of these channels was 1:2 (250- $\mu$ m-deep: $500-\mu \mathrm{m}-$ wide). We believe that an aspect ratio of at least 1:1 should be possible for these microfluidic structures. Figure 4C shows photographs of two of the empty cellophane-based microfluidic devices with the embossed features facing up; Figure 4A,4B show the cross sections of these microfluidic channels, and Figure 4G shows the transparency of the devices.

The microfluidic structures were formed in the first step through purely mechanical deformation of the cellophane since cellophane is not thermoplastic. As a result, when the cellophane was heated in the second step, the surface coating melted (to provide heat-sealing), but the microfluidic structure was not altered by the heat. Both the embossing and heat-sealing steps of the fabrication technique could be completed in less than 2 minutes. The use of only dry materials simplifies the procedure and reduces cost. This process, therefore, has the potential to be scaled to large volumes using high-throughput printing techniques such as roll-to-roll manufacturing. 


\section{Basic microfluidic operation}

We demonstrated pressure-driven flows, and imaged a series of dyes in transmission mode, in a device with the Y-junction design. Figure 5A shows a top view of a cellophane microfluidic device with two inlets connecting a Y-junction to a serpentine channel and one outlet.

We injected two aqueous solutions of dyes (Acid Red, and Reactive Blue) at flow rates ranging from $10 \mu \mathrm{L} / \mathrm{min}$ to $200 \mu \mathrm{L} / \mathrm{min}$, and observed laminar flow (Figure 5C) in this regime (we could do both pressure- or vacuum-driven flows using this setup). The Reynolds numbers in this regime are below 10 (this value is approximate, and based on water flowing in a channel with a circular cross-section). ${ }^{35}$ The edges of the microfluidic channels were sharp; the definition of these shapes indicates tight and well-defined sealing. We observed no leakage or breakage from the inlets or at the edges of the channels (which could have occurred either as a result of delamination or film puncture during molding). These experiments showed that the cellophane microfluidic system (both the $1000-\mu \mathrm{m}$-wide, and 500- $\mu \mathrm{m}$-wide channels) could support flow rates up to $200 \mu \mathrm{L} / \mathrm{min}$, under pressure-driven flow, without leakage. Using the Darcy-Weisbach equation, we calculated the corresponding pressure drop for water $\left(25^{\circ} \mathrm{C}\right)$ flowing at $200 \mu \mathrm{L} / \mathrm{min}$ to $5 \mathrm{kPa}$ for the $1000-\mu \mathrm{m}$-wide channels, and $70 \mathrm{kPa}$ for $500-\mu \mathrm{m}$-wide channels (see SI for calculations).

Since the device consists of only two sheets of cellophane, including the thin coating on each side of the sheets, it is thin (around 75- $\mu \mathrm{m}$-thick, as seen in Figure 4E,4F), and flexible. Figures 5A shows a microfluidic device that is bent during a continuous flow of the two liquids. The devices were easily bendable to a radius of 
curvature of 1-2 cm without any noticeable change in the flow behavior or damage of the microfluidic structure.

\section{Generation of droplets and slugs in multiphase flow}

We used hexadecane (transparent) and an aqueous solution of a blue dye (Reactive Blue) to show the compatibility of the microfluidic channels to other solvents and the formation of different liquids. Hexadecane and the aqueous solution were injected into the T-junction device to form slugs (Figure 5C).

\section{Static mixers}

Mixing is important for many microfluidic applications. ${ }^{34} \mathrm{We}$ used the serpentine microchannels in the device with the T-shaped inputs. Figure $6 \mathrm{C}$ shows a photo of the T-junction device where two miscible aqueous dyes (blue and yellow) were pumped at a flow rate of $2 \mu \mathrm{L} / \mathrm{min}$. At this flow rate, the dyes were co-flowing without convective mixing. After passing through the serpentine channels, the flows mixed and formed a single green-colored stream. Mixing occurred through diffusion, and could also be enhanced by chaotic advection using the turns in serpentine channels. $^{34}$

We also explored paper as a material for mixing. We used the designs with a Y-shaped input and larger channels (1-mm wide). We cut $1 \mathrm{~mm}$-wide pieces of filter paper (Whatman grade 1) and placed them in a section of the channel before sealing the device (see schematics of fabrication in Figure 6A). We chose Whatman grade 1, because it is a paper with a well-defined pore size that wicks water well, and because it is stable in water (the fibers do not disintegrate when wet). Other papers would probably work as well; we did not explore a range. The porosity, and tortuosity of the 
filter paper accelerated the mixing of the two fluids (Figure 6B). The advantage of this mixer is that it is more rapid, and requires shorter channels, than serpentine mixers (the length of the paper zone was $10 \mathrm{~mm}$ ). Paper has been extensively used as a substrate for storage of biomolecules ${ }^{30,36,37}$, so the ability to incorporate paper into the cellophane-based device, may also take advantage of its large surface area and surface chemistry for the storage and release of reagents.

\section{Electroanalytical devices}

The integration of electrodes in microfluidic systems ${ }^{38}$ enables the development of electroanalytical devices, and is often achieved by patterning electrodes (usually metals, patterned using vapor deposition) in one of the plates of the device (e.g. on polymer or glass substrates) and then sealing a second plate that includes microfluidic channels. The use of carbon electrodes in electroanalysis is attractive, because they have a wide potential window in aqueous solutions, and low cost. For example offdevice configurations, using screen-printed carbon electrodes on substrates placed perpendicularly to closed microfluidic devices, ${ }^{39}$ or channels that incorporate embedded carbon paste, have been reported. ${ }^{40}$

One of the interesting features of cellophane is its ability (like paper) to be used as a substrate for printing, with the added advantage of very low surface roughness. We exploited this property to integrate electrodes into cellophane microfluidic devices. We printed electrodes with graphite ink, using stencil printing, on coated cellophane $\left(\mathrm{C}^{\mathrm{PVC}}\right)$, and sealed these sheets against the embossed features (see schematics in Figure 7A and methods). The printed electrodes adhered strongly to the cellophane sheets, and could also be sealed tightly against the embossed sheet, so that the device did not delaminate. The sealing was also conformal between the 
regions with the electrodes and the bare substrate so that no water escaped from the channel into the regions around the electrodes. As a result, we could fabricate printed electrodes integrated into the microfluidic channels.

To evaluate the performance of the integrated electrochemical cell electrodes, we performed flow injection analysis, by pumping a supporting electrolyte over a three-electrode electrochemical cell where all three electrodes were printed in a single step using carbon ink. We designed the working electrode (1-mm width) to be positioned before the counter electrode $(2.5 \mathrm{~mm}$ width $)$, so that any substances that could be produced by electrolysis at the counter electrode would not reach the working electrode and cause interference. A carbon electrode (1 mm width) acted as a quasi-reference electrode (see Figure 7B). All electrodes were connected to a potentiostat using small copper clips.

A common electrochemical technique used in microfluidic devices is potentiostatic amperometry. ${ }^{41,42}$ In this technique, a fixed potential — at which electron transfer occurs - is applied to the working electrode and the current is continuously recorded $v s$. time. After the baseline current (measured using continuous flow of the buffer) is allowed to stabilize, the sample is injected, and the signal it generates is recorded $v s$. time (see Figure S5), until a plateau current is reached. We used the cellophane-based system for amperometric detection of the redox probe, potassium ferrocyanide (concentrations between $10 \mu \mathrm{M}$ to $10 \mathrm{mM}$ ), at a potential of $0.4 \mathrm{~V}$ ( $v s$. a carbon quasi-reference electrode) applied to the working electrode. We observed a linear relationship between the ferrocyanide concentration and the difference between the plateau current to the baseline current (Figure 7C), over this concentration range $(n=7)$. This linearity indicates that this system can in principle be used for quantitative determination of an electroactive analyte. 
To further exploit the inherent transparency of cellophane in combination with electroanalysis, we fabricated electrochemical cellophane microfluidic devices for use in continuous flow ECL detection. These devices were similar to those used for continuous flow electroanalysis of ferrocyanide, with the exception that the reference electrode was printed with an $\mathrm{Ag} / \mathrm{AgCl}$ ink. $\mathrm{ECL}$ is among the most sensitive analytical techniques, and it is commonly employed for immunoassays at many routine hospital laboratories using clinical autoanalyzers. ${ }^{43}$

For the cellophane ECL system, we chose a reaction between $\mathrm{Ru}(\mathrm{bpy})_{3}{ }^{2+}$ (luminophore) and L-proline (analyte), because this reaction has been extensively studied. ${ }^{44-46}$ The ECL reaction mechanism, ${ }^{47,48}$ in short, starts with the electrochemical oxidation of $\mathrm{Ru}(\mathrm{bpy}){ }_{3}{ }^{2+}$ to $\mathrm{Ru}(\mathrm{bpy}){ }_{3}{ }^{3+}$ at the electrode surface. Proline is then oxidized by $\mathrm{Ru}(\mathrm{bpy}){ }_{3}{ }^{3+}$ to produce a free radical [proline] ${ }^{\bullet}$, which undergoes spontaneous deprotonation to produce an intermediate radical ion that reacts with $\mathrm{Ru}(\mathrm{bpy})_{3}{ }^{3+}$ to produce the excited state $\left[\mathrm{Ru}(\mathrm{bpy})_{3}{ }^{2+}\right]^{*}$. The excited $\left[\mathrm{Ru}(\mathrm{bpy})_{3}{ }^{2+}\right]^{*}$ finally decays to its ground state, $\mathrm{Ru}(\mathrm{bpy}) 3^{2+}$, and emits orange light at $620 \mathrm{~nm}$ (See SI for the balanced chemical equations for these reactions). If the concentration of the luminophore is kept constant, the intensity of the emitted light is directly related to the concentration of the analyte.

A cyclic voltammogram of $\mathrm{Ru}(\mathrm{bpy})_{3}{ }^{2+}$ showed that the electrodes printed inside cellophane microfluidic channels were stable in the range of potentials used for our experiments, and that the channels did not leak or change dimension significantly during operation (see Figure S6). In the continuous flow ECL experiments, the analyte and the luminophore are injected into a common channel where they co-flow and pass the electrodes at a constant flow rate. For the ECL measurements in cellophane $\mathrm{C}^{\mathrm{PVC}}$ devices, we injected both the analyte and the luminophore at a 
constant flow rate of $10 \mu \mathrm{L} / \mathrm{min}$, applied a potential of $1.25 \mathrm{~V}$ (vs. $\mathrm{Ag} / \mathrm{AgCl})$, and measured the resulting ECL light response for a period of 0.5 seconds (see methods, and Figure 7E). We observed a linear relationship between the integrated area of the ECL response and the concentration of proline (Figure 7D), in the concentration range between $0.1 \mu \mathrm{M}$ to $10 \mu \mathrm{M}(\mathrm{n}=9)$. This proof- of-concept demonstration promises useful future applications of cellophane in ECL diagnostic applications. ${ }^{45,49,50}$

\section{Integrated heaters}

The ability to print conductors on cellophane also enables the integration of electrical function intended for applications other than electroanalysis. One useful example is electrical heating. We integrated a resistive heating device into the cellophane $\mathrm{C}^{\mathrm{PVC}}$ microfluidic devices by printing a carbon structure on the back side of a device (see Figure 8). Since the cellophane is thin, heating is restricted to the regions immediately adjacent to the heater, and heating of the liquid in the channel is rapid.

\section{Conclusions}

Here we demonstrate microfluidic systems based on films from regenerated cellulose (cellophane), which is either uncoated, $\left(\mathrm{C}^{\mathrm{OH}}\right)$, or has thin surface $(\sim 1 \mu \mathrm{m})$ coatings of nitrocellulose $\left(\mathrm{C}^{\mathrm{NS}}\right)$, or polyvinyl chloride $\left(\mathrm{C}^{\mathrm{PVC}}\right)$. We show that cellophane $\mathrm{C}^{\mathrm{OH}}$ can be used to fabricate microplates, and that cellophane $\mathrm{C}^{\mathrm{NS}}$ or $\mathrm{C}^{\mathrm{PVC}}$ can be used to fabricate open-channel microfluidic devices that incorporate channels with moderately small dimensions $(\sim 500 \mu \mathrm{m})$ and complex geometries. We also show that electrodes can be printed onto the microfluidic devices to integrate resistive heating elements, and more importantly that they can be embedded in the microfluidic 
channels, to enable the fabrication of electroanalytical devices and continuous-flow ECL devices.

Cellophane $\mathrm{C}^{\mathrm{PVC}}$ and $\mathrm{C}^{\mathrm{NS}}$ are attractive materials for microfluidic systems that require high throughput manufacturing at low cost, and optical transparency because they heat seal under conveniently attainable conditions. Cellophane microfluidic devices combine some of the advantages of cellulose-based paper microfluidics with new capabilities. They have at least six useful characteristics: i) The fabrication processes are potentially scalable to manufacturing levels, and low in cost (through, for example, roll-to-roll manufacturing). ii) They enable open-channel systems with useful resolution $(\sim 500 \mu \mathrm{m}$ in this work, but we believe that higher resolution should be possible). They also enable transparent electroanalytical microfluidic devices that can be fabricated using high-throughput printing techniques. iii) They have a high optical transparency in both the UV and visible regime; cellophane $\mathrm{C}^{\mathrm{OH}}$ has the highest transparency in the UV region of the cellophane varieties that we analyzed in this work. iv) They are resistant to destruction by many solvents. v) They are thin (around $70 \mu \mathrm{m}$ ) and flexible. vi) They are easily disposable, through biodegradation or incineration. The main disadvantages of cellophane $\mathrm{C}^{\mathrm{OH}}$ as a microfluidic material are that it absorbs water, and therefore changes dimensions. Furthermore, bonding of cellophane $\mathrm{C}^{\mathrm{OH}}$ is not possible without an adhesive, since cellulose neither dissolves easily in any solvent, nor is it thermoplastic. Cellophane $\mathrm{C}^{\mathrm{OH}}$ is useful for microplate applications that require optical transparency (especially in the UV region), solvent resistance, and biocompatibility.

Cellophane is both a complement to cellulose-based paper for microfluidic devices, and also an alternative to other materials currently used in microfluidics, such as PDMS, cyclic olefin copolymers (COC), PMMA, PS, and glass or quartz. We 
believe that regenerated cellulose films or other forms of cellulose films ${ }^{9}$, such as nanocellulose paper, ${ }^{51,52}$ may find uses in disposable integrated microfluidic systems for diagnostics, cell culture, and MEMS.

\section{Acknowledgements}

M. M. H. acknowledges support from Marie Curie IOF FP7 for project nanoPAD (Grant Agreement Number 330017), the Bo Rydins stiftelse (SCA AB), and the Sweden-America Foundation. E.K. thanks Endeavour Scholarships and Fellowships, DFAT, Australian Government. M.T.F.A. thanks the University of Oviedo through the Campus de Excelencia Internacional for partially funding her stay at Harvard University. A.G. acknowledges support from DTRA contract \# HDTRA1-14-C-0037. B.U. acknowledges support from DoE award ER45852. We thank Gulden CamciUnal for her help with the SEM images of the cellophanes. We also thank Jason Harper and Innovia Films for providing the cellophane materials. 


\section{FIGURES AND TABLES}

Table 1. Properties of regenerated cellulose films (uncoated cellophane).

\begin{tabular}{|c|c|c|}
\hline Property & Values & Reference \\
\hline Dielectric constant & 4 at $1 \mathrm{MHz}$ & \\
\hline Dielectric strength & $3050 \mathrm{kV} \mathrm{mm}^{-1}$ at $1 \mathrm{~mm}$ & 53,54 \\
\hline Density & $1.44 \mathrm{~g} \mathrm{~cm}^{-3}$ & 53,54 \\
\hline $\begin{array}{l}\text { Tensile strength (MPa), } \\
\text { and elongation at break }\end{array}$ & $120 \mathrm{MPa}(20 \%)$ for machine direction. & 27,54 \\
\hline$(\%)$ & $70 \mathrm{MPa}(70 \%)$ for transverse direction & \\
\hline Index of refraction, and & 1.468 (machine direction). & 55 \\
\hline birefringence & 1.472 (transverse direction). & \\
\hline & $\begin{array}{l}\text { Birefringence } 0.0041 \text {, with a phase shift } \\
\text { of } 0.98 \pi \text { radians for a } 24-\mu \text { m-thick film. }\end{array}$ & \\
\hline Price & $\begin{array}{l}5 \mathrm{USD} / \text { pound } \\
\text { or } 0.8 \mathrm{USD} / \mathrm{m}^{2} \text { sheets }(50-\mu \mathrm{m} \text {-thick })\end{array}$ & 27 \\
\hline Water absorption after $24 \mathrm{~h}$ & $45-115$ (weight \%) & 54 \\
\hline Solvent compatibility & $\begin{array}{l}\text { Dilute acids and alkalis, most organic } \\
\text { solvents (polar and non-polar), and most } \\
\text { oils. We tested hexadecane, glycerol, } \\
\text { ethylene glycol, ethanol, DMSO, NMP, } \\
\text { THF, NMP, DMF (see methods). }\end{array}$ & 15,54 \\
\hline Thermal expansion & $8 \times 10^{-5} \mathrm{~K}^{-1}$ & 53 \\
\hline Upper temperature for use & $180 \mathrm{C}^{\circ}$ & 54 \\
\hline Biodegradation & $\begin{array}{l}\text { Films were fully decomposed after } 2 \\
\text { months in soil. }\end{array}$ & 13 \\
\hline
\end{tabular}


Table 2. Analytical figures of merit for absorption measurement of different compounds in uncoated cellophane 96-well plates (see Figure 2). $10 \mu \mathrm{L}$ of solution was used in each well (for the regression analysis, the confidence interval is $95 \%$, and the number of samples $n=7$ ).

\begin{tabular}{llllll}
\hline Analyte & $\begin{array}{l}\lambda_{\max } \\
(\mathbf{n m})\end{array}$ & $\begin{array}{l}\text { Measured } \\
\text { range } \\
(\boldsymbol{\mu g} / \mathbf{m L})\end{array}$ & $\mathbf{R}^{2}$ & $\begin{array}{l}\text { Slope } \\
(\mathbf{S})\end{array}$ & $\begin{array}{l}\mathbf{L O D}^{\mathbf{a}} \\
(\boldsymbol{\mu g} / \mathbf{m L})\end{array}$ \\
\hline Thiamine & 238 & $20-500$ & 0.995 & 0.001 & 8 \\
Acetaminophen & 242 & $20-500$ & 0.995 & 0.003 & 8 \\
Adenine & 260 & $2.6-675$ & 0.998 & 0.003 & 6 \\
\hline
\end{tabular}

${ }^{\mathrm{a}} \mathrm{LOD}=3.3\left(\mathrm{~S}_{\mathrm{y}} / \mathrm{S}\right), \mathrm{S}_{\mathrm{y}}=$ Standard deviation of the intercept, $\mathrm{S}=$ Slope 

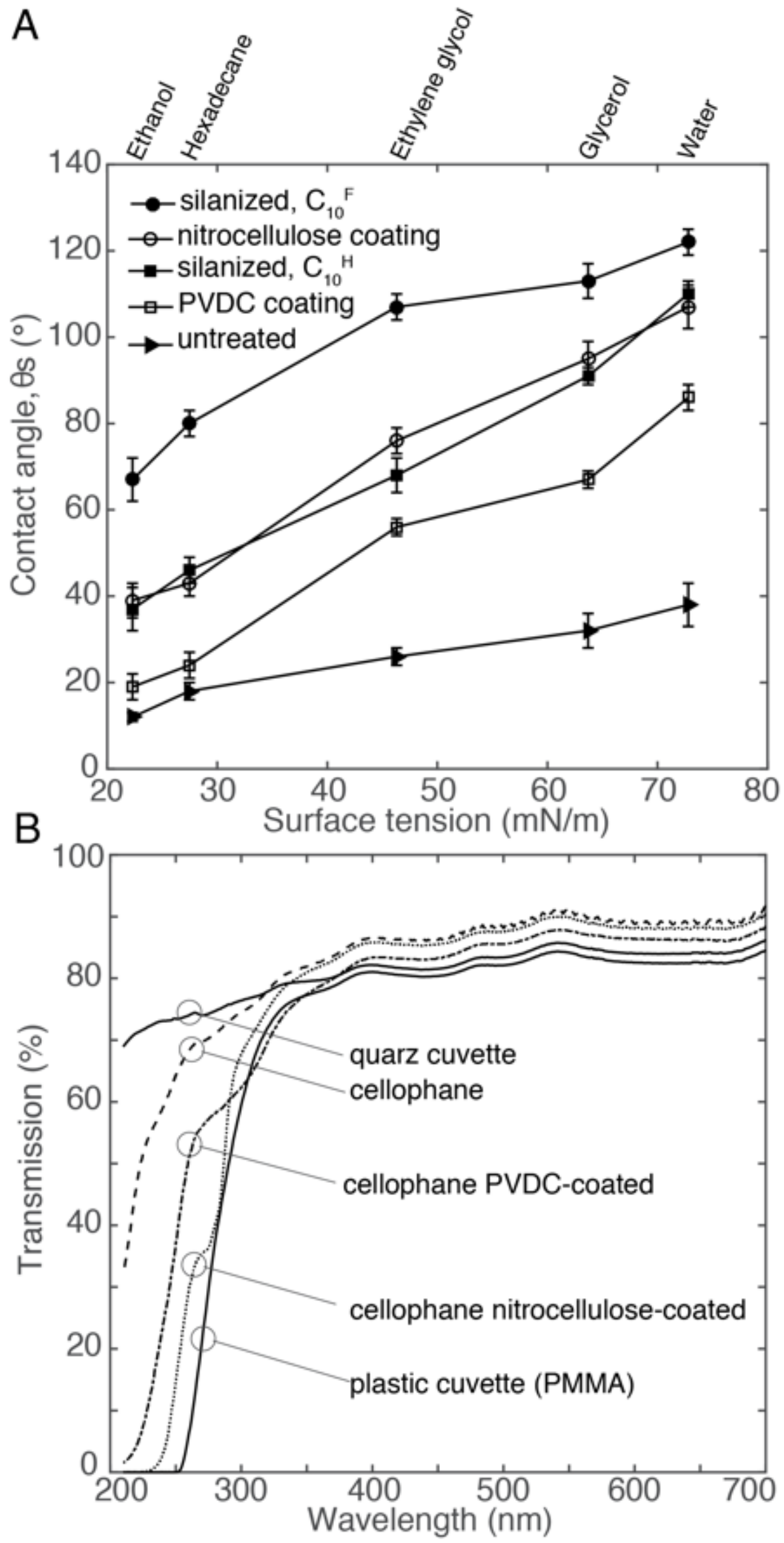
Figure 1 A) The correlation of static contact angles on surface tension for $10 \mu \mathrm{L}$ droplets of liquid on uncoated cellophane $\mathrm{C}^{\mathrm{OH}}$, cellophane with PVC- and nitrocellulose coatings $\left(\mathrm{C}^{\mathrm{PVC}}, \mathrm{C}^{\mathrm{NS}}\right)$, and cellophane $\mathrm{C}^{\mathrm{OH}}$ silanized with either a fluorinated $\left(\mathrm{C}_{10}{ }^{\mathrm{F}}\right)$ or a non-fluorinated $\left(\mathrm{C}_{10}{ }^{\mathrm{H}}\right)$ alkyl silane (standard deviation are based on $n=7$ ). The liquids used in these experiments and their respective surface tensions at $20^{\circ} \mathrm{C}$ in $\mathrm{mN} / \mathrm{m}$ are: anhydrous ethanol (22.3), hexadecane (27.4), ethylene glycol (46.3), glycerol (63.7), water (72.8). B) Normalized UV-Visible transmission spectra of different sheets of cellophane (uncoated $34 \mu \mathrm{m}$ thick, nitrocellulose-coated $42 \mu \mathrm{m}$ thick, PVC-coated $42 \mu \mathrm{m}$ thick), PMMA cuvette, and quartz cuvette (500- $\mu \mathrm{m}$ thick). 

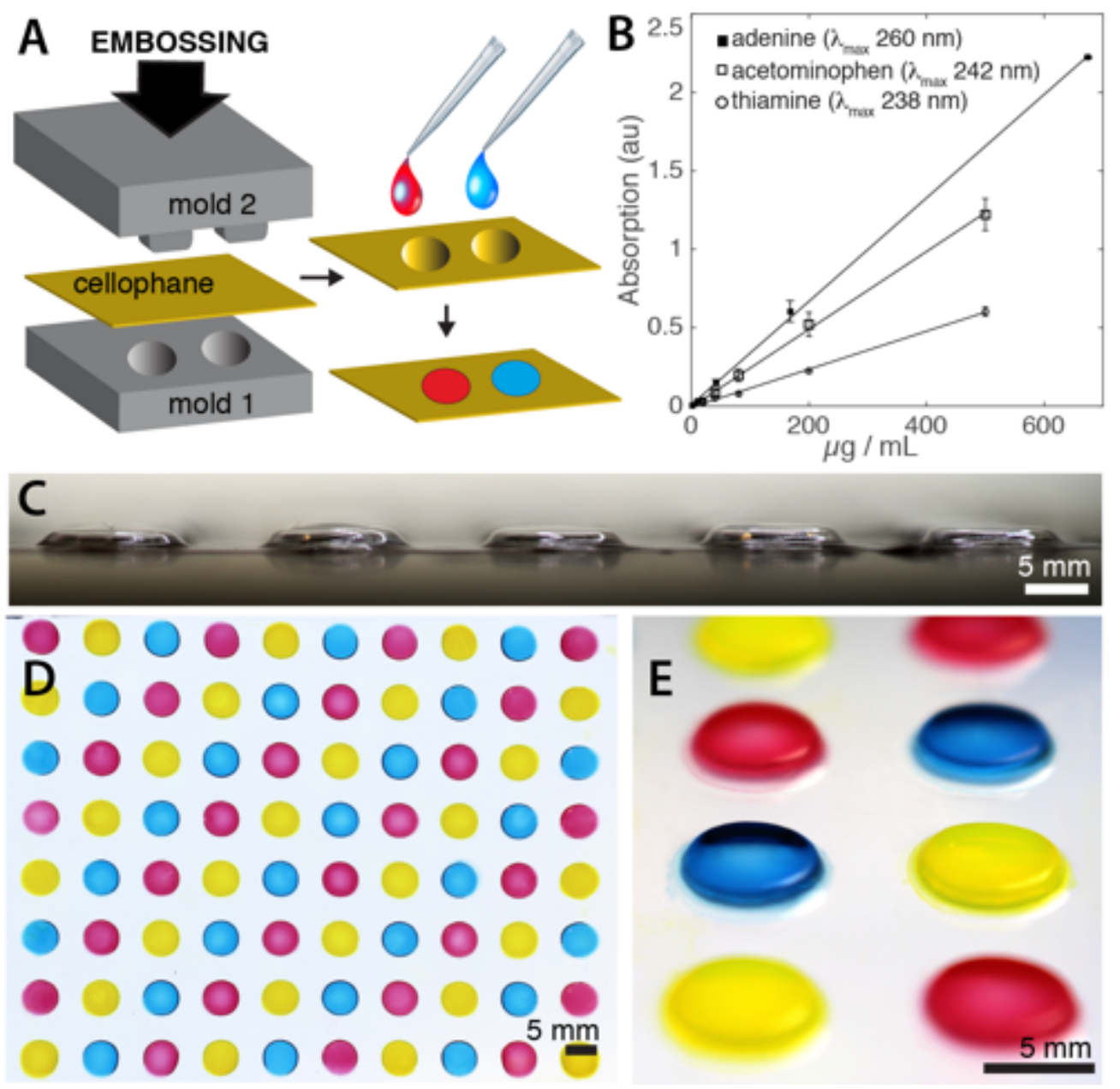

Figure 2 A) Schematic flow diagram for the fabrication and use of uncoated cellophane $\left(\mathrm{C}^{\mathrm{OH}}\right)$ 96-well microplates. B) UV Absorption of different analytes measured in cellophane $\mathrm{C}^{\mathrm{OH}}$ 96-well plates using $10 \mu \mathrm{L}$ of solution in each well $(n=7)$. For a complete set of data see Table 2. C) Macro photograph of the cross section of a cellophane $\mathrm{C}^{\mathrm{OH}}$ (pre-wetted) 96-well plate. D) Top view photographs of a cellophane (non-coated) 96-well plate, in which each well is filled with $10 \mu \mathrm{L}$ of aqueous solutions (red: Acid Red, blue: Reactive Blue, yellow: Food color) E) Bottom view macro photographs of the same microplate as in 2D). 
1. Embossing

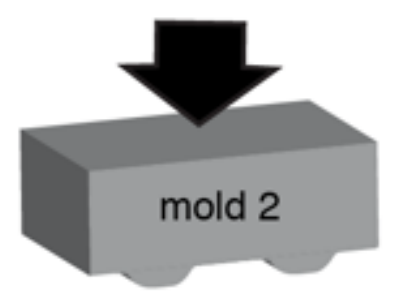

coated cellophane L1
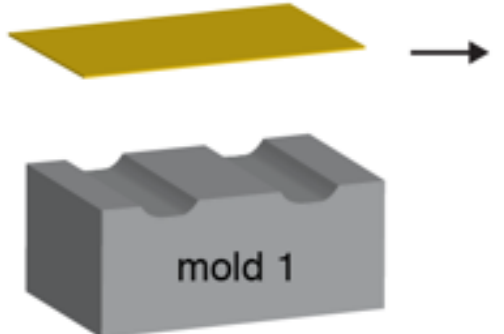

2. Sealing

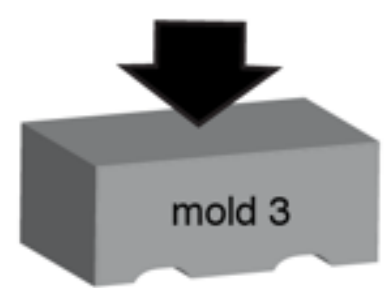

mold 1
3. Connection

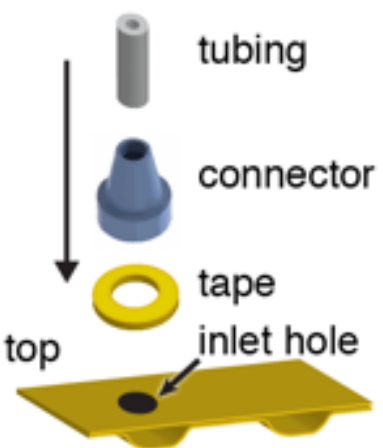

bottom

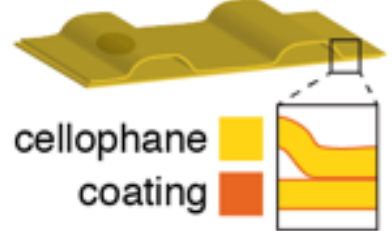

Figure 3 Schematic flow diagram for the construction of the coated cellophane $\left(\mathrm{C}^{\mathrm{PVC}}\right.$, or $\mathrm{C}^{\mathrm{NS}}$ ) microfluidic devices. There are three steps in this process: (1) embossing the channels using a first layer (L1) of coated cellophane (2), sealing the device using a second layer (L2) of coated cellophane, and (3) interfacing the device with the fluidic connections and tubing. 


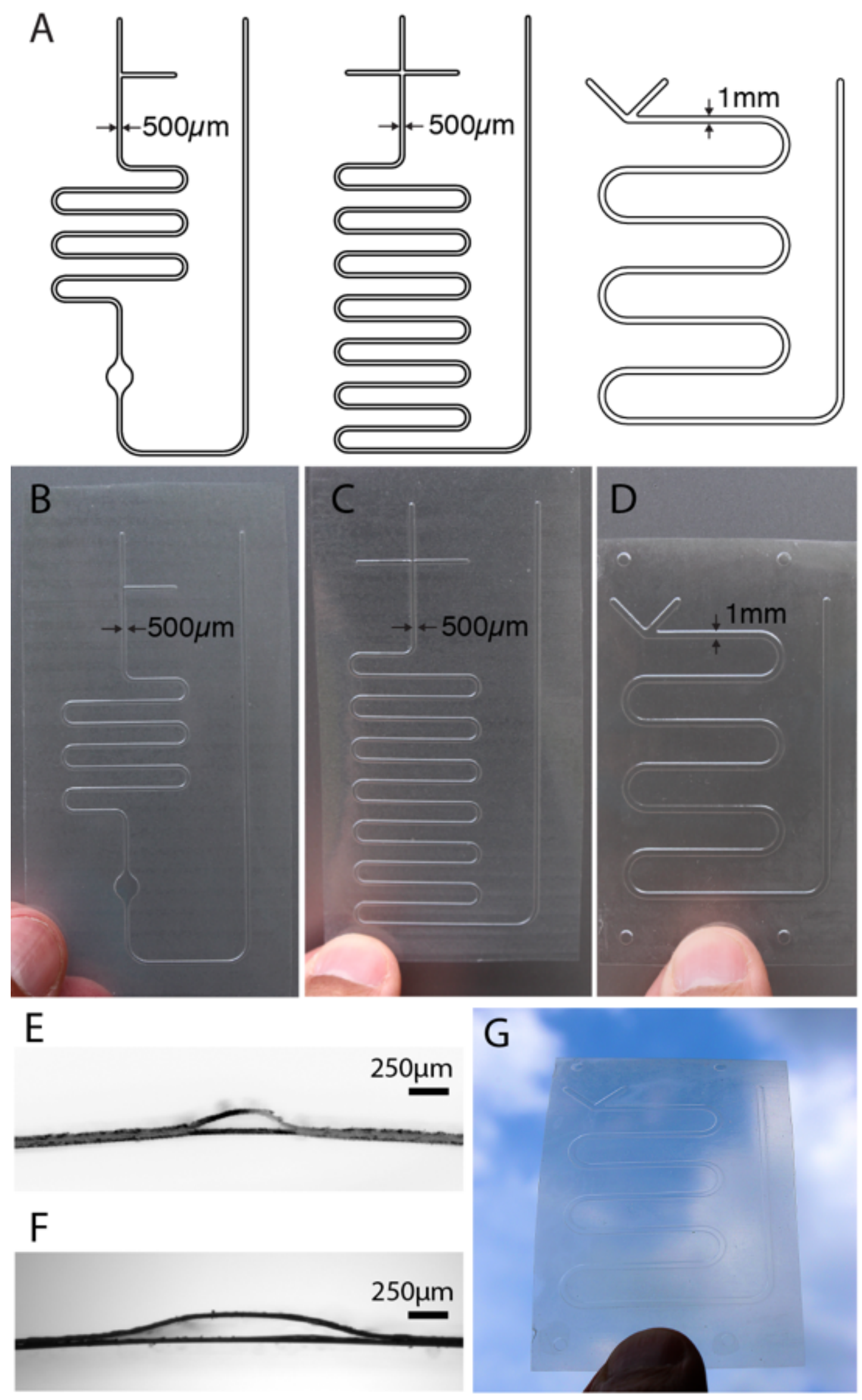


Figure 4 A) Schematic diagrams of three different microfluidic devices.

B,C,D) Photographs of PVC-coated cellophane $\left(\mathrm{C}^{\mathrm{PVC}}\right)$ microfluidic devices with the embossed features facing up. The devices were fabricated using aluminum molds with different structure according to A). E) Microscope photograph of cross section of a channel fabricated using a mold with the structure on B, C) (500 $\mu \mathrm{m}$ channel width). F) Microscope photograph showing the cross sections of a channel fabricated using a mold with the structure on D) (1-mm channel width). All cross sections were cut using scissors. G) Photographs of cellophane $\mathrm{C}^{\mathrm{PVC}}$, taken against a sky with clouds to show transparency. 


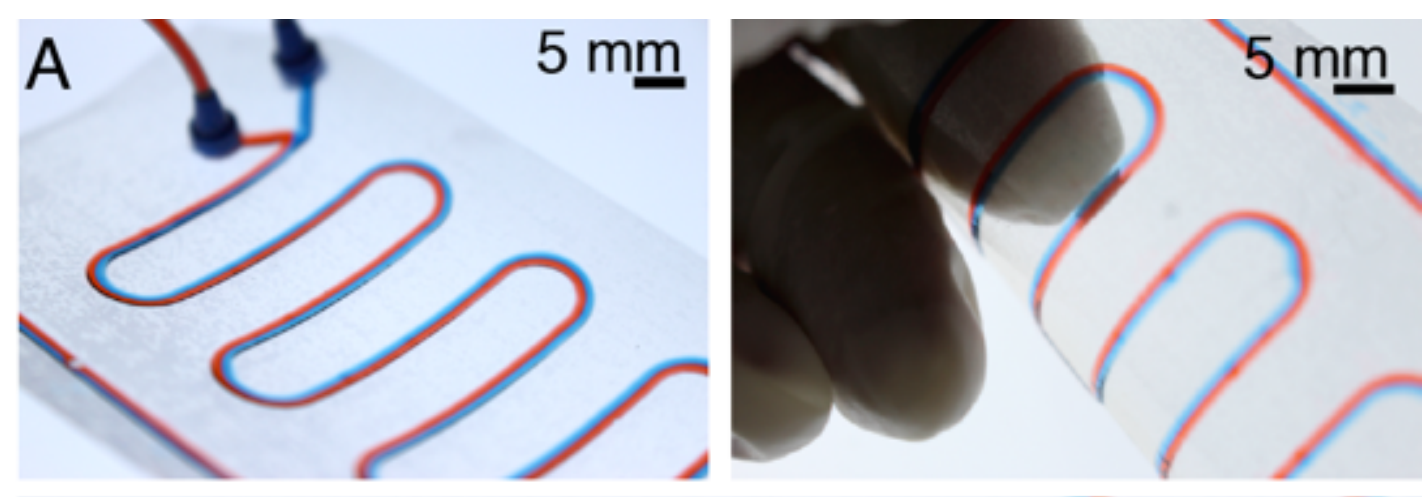

B

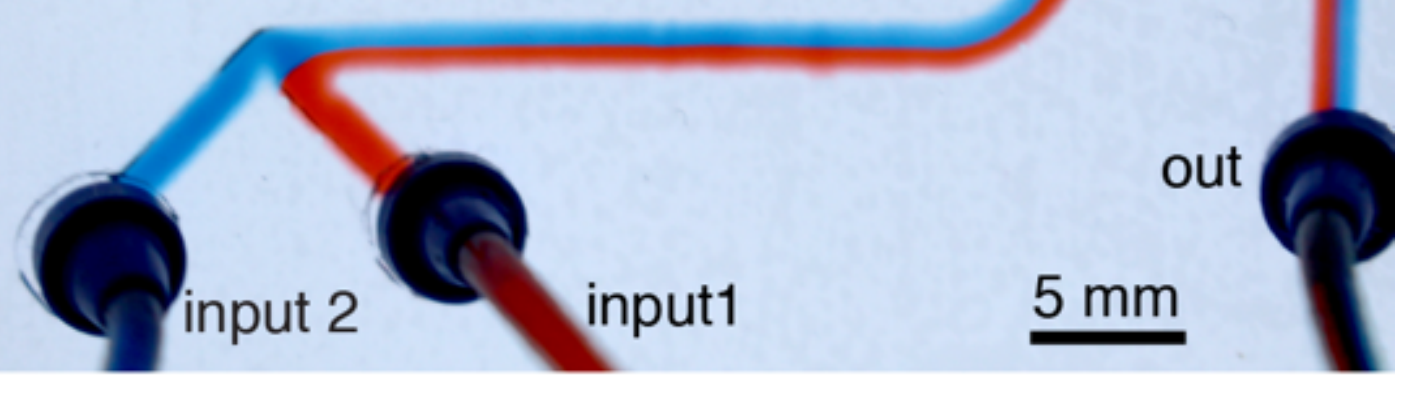

C

hexadecane
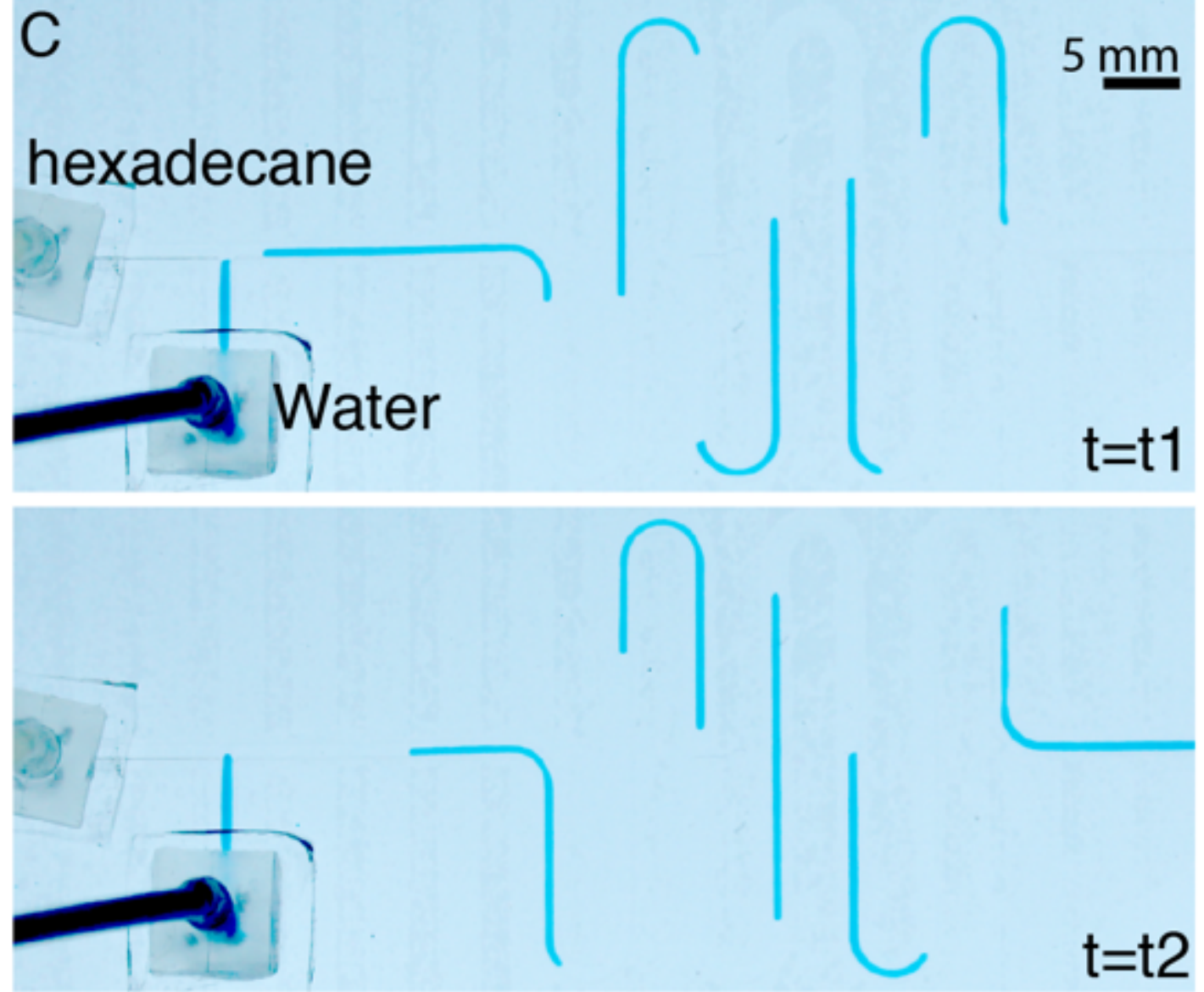
Figure 5 A) (left) Photographs of the Y-junction microfluidic device, fabricated with nitrocellulose-coated cellophane $\left(\mathrm{C}^{\mathrm{NS}}\right)$, displaying a laminar flow created by pumping red (input 2) and blue (input 1) aqueous dyes at a speed of $50 \mu \mathrm{L} / \mathrm{min}$. (right) photographs of the device in 4A under operation while it is bent. B) Zoom in photograph of 4A. C) A) Photographs of multiphase flow using the T-junction cellophane microfluidic device, showing the generation of slugs in a hexadecane / water system (both solutions had a flow rate of $30 \mu \mathrm{L} / \mathrm{min}$ ). 

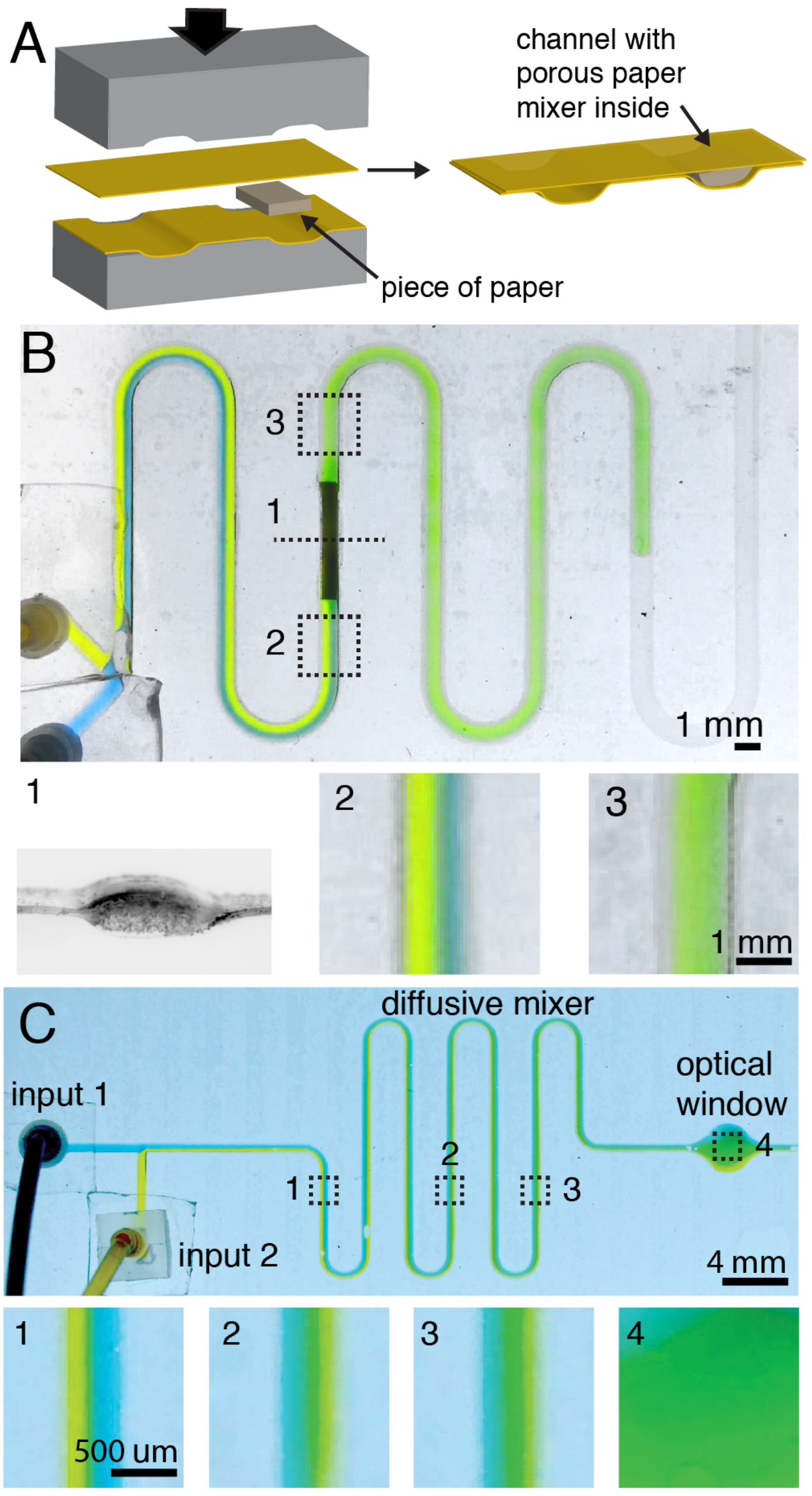
Figure 6 A) Schematic diagram of the fabrication of a cellophane $\mathrm{C}^{\mathrm{PVC}}$ microfluidic device with a porous static mixer. B) Photographs of a cellophane $\mathrm{C}^{\mathrm{PVC}}$ microfluidic device with a porous static mixer. The porous mixer is a piece of paper placed within the channel as seen in the cross-section photo (1). Two aqueous solutions of a blue and a green dye (food color) flowed at a speed of $20 \mu \mathrm{L} / \mathrm{min}$ before (2) and after (3) entering into the mixer. C) Photograph of a T-junction microfluidic device with two aqueous dyes (blue color at input 1, and yellow color at input 2) are pumped at a flow speed of $2 \mu \mathrm{L} / \mathrm{min}$ for each solution. The dyes have a laminar flow behavior at the beginning of the channel and subsequently mix with each other with diffusion mixing. 


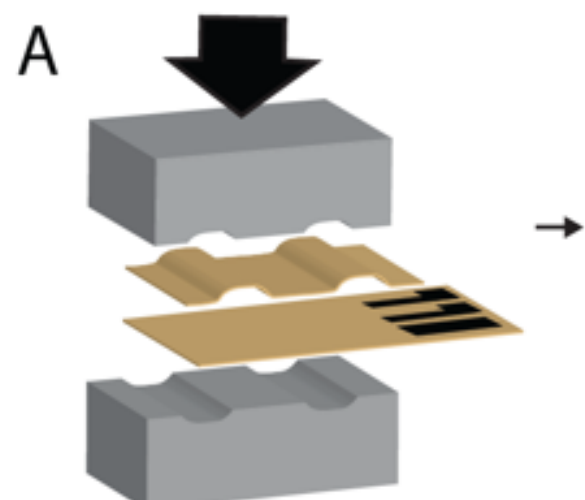

Amperometry

B

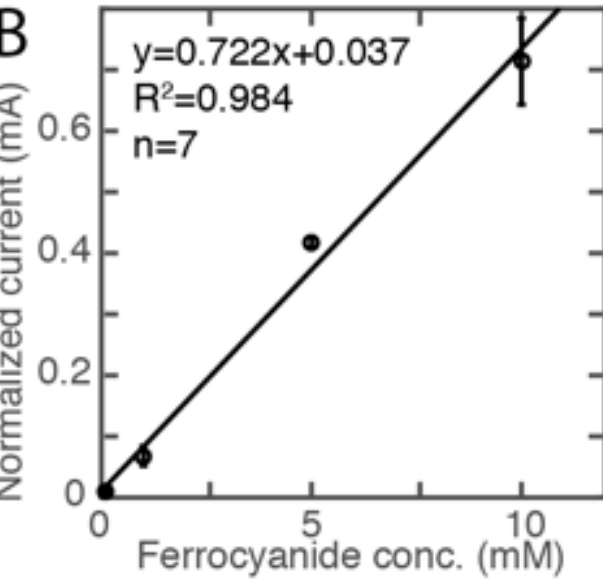

ECL Light

Flow

Detector
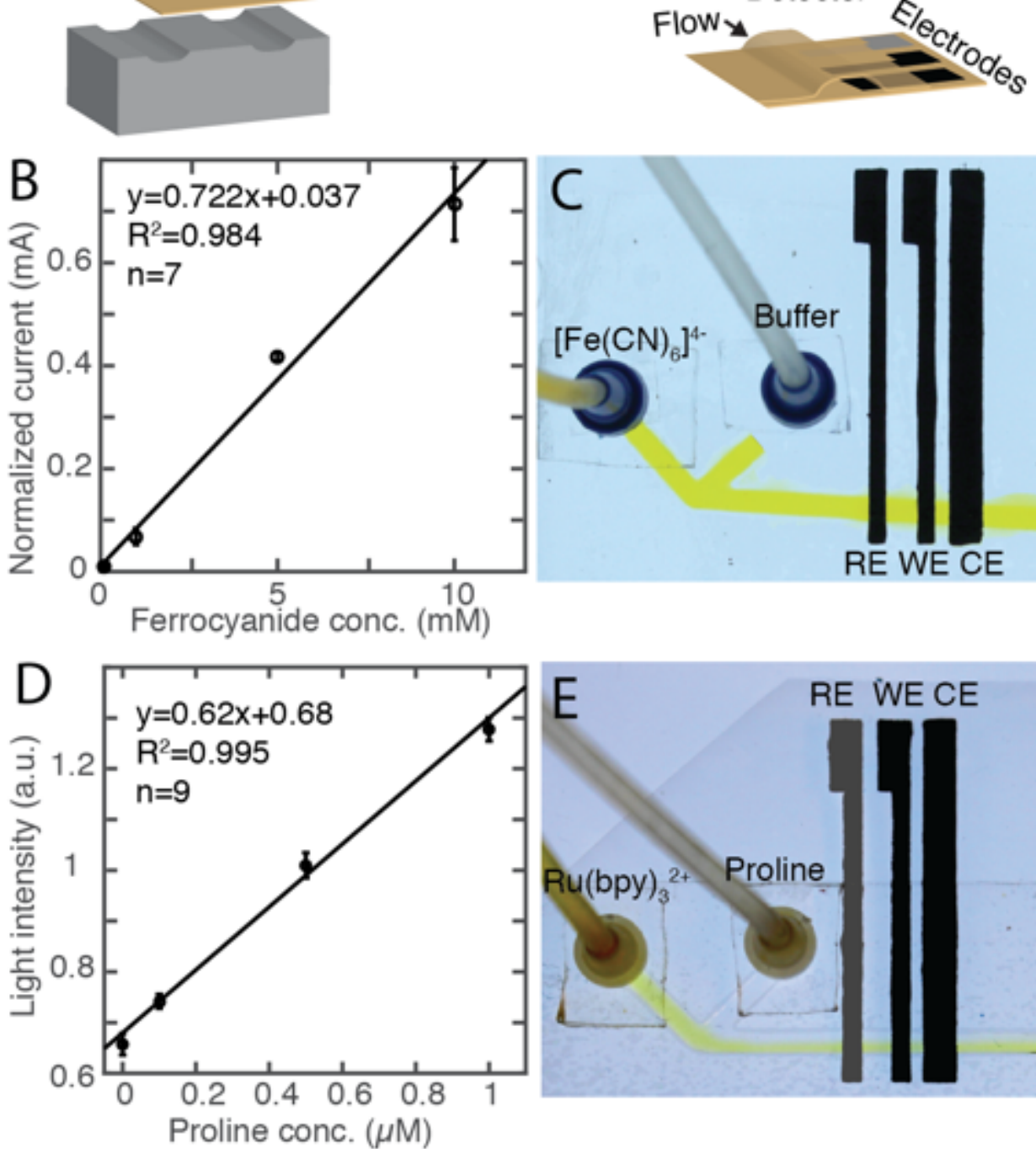

Proline conc. $(\mu \mathrm{M})$ 
Figure 7 A) Schematic diagram of the fabrication of a coated cellophane microfluidic device with carbon, and $\mathrm{Ag} / \mathrm{AgCl}$ electrodes printed inside the channels. B) Results obtained, using a cellophane $\mathrm{C}^{\mathrm{PVC}}$ device shown in Figure $7 \mathrm{C}$, by potentiostatic amperometry ( $+0.4 \mathrm{~V} v s$. carbon quasi-reference) for potassium ferrocyanide. The ferrocyanide (in phosphate-buffered saline 1xPBS) was injected from the sample inlet at different concentration ( 0.1 to $10 \mathrm{mM})$ at a constant flow rate of $50 \mu \mathrm{L} / \mathrm{min}$. A buffer solution (phosphate-buffered saline 1xPBS) was pumped at $50 \mu \mathrm{L} / \mathrm{min}$ between each injected sample solution $(n=7)$, to acquire a baseline current for normalization. C) Photograph of a cellophane $\mathrm{C}^{\mathrm{PVC}}$ device with carbon electrodes integrated into the channel, which is filled with a highly concentrated solution of ferrocyanide flowing at $50 \mu \mathrm{L} / \mathrm{min}$. D) Results obtained for EC, using a cellophane $\mathrm{C}^{\mathrm{PVC}}$ device shown in Fig. E, by potentiostatic amperometry $(1.25 \mathrm{~V} v s . \mathrm{Ag} / \mathrm{AgCl})$ for the reaction of $\mathrm{Ru}(\mathrm{bpy})_{3}{ }^{2+}$ $(2 \mathrm{mM})$ with L-proline $(0.1$ to $1 \mu \mathrm{M})$. Both $\mathrm{Ru}(\mathrm{bpy}){ }_{3}{ }^{2+}$ and L-proline were injected at a constant flow rate of $10 \mu \mathrm{L}$ per minute $(\mathrm{n}=9)$. E) Photograph of an ECL cellophane $\mathrm{C}^{\mathrm{PVC}}$ device with a carbon working- and counter-electrode, and an $\mathrm{Ag} / \mathrm{AgCl}$ reference electrode integrated into the channel. The channel is filled with a solution of $\mathrm{Ru}(\text { bpy })_{3}{ }^{2+}$ flowing at $10 \mu \mathrm{L} / \mathrm{min}$. 

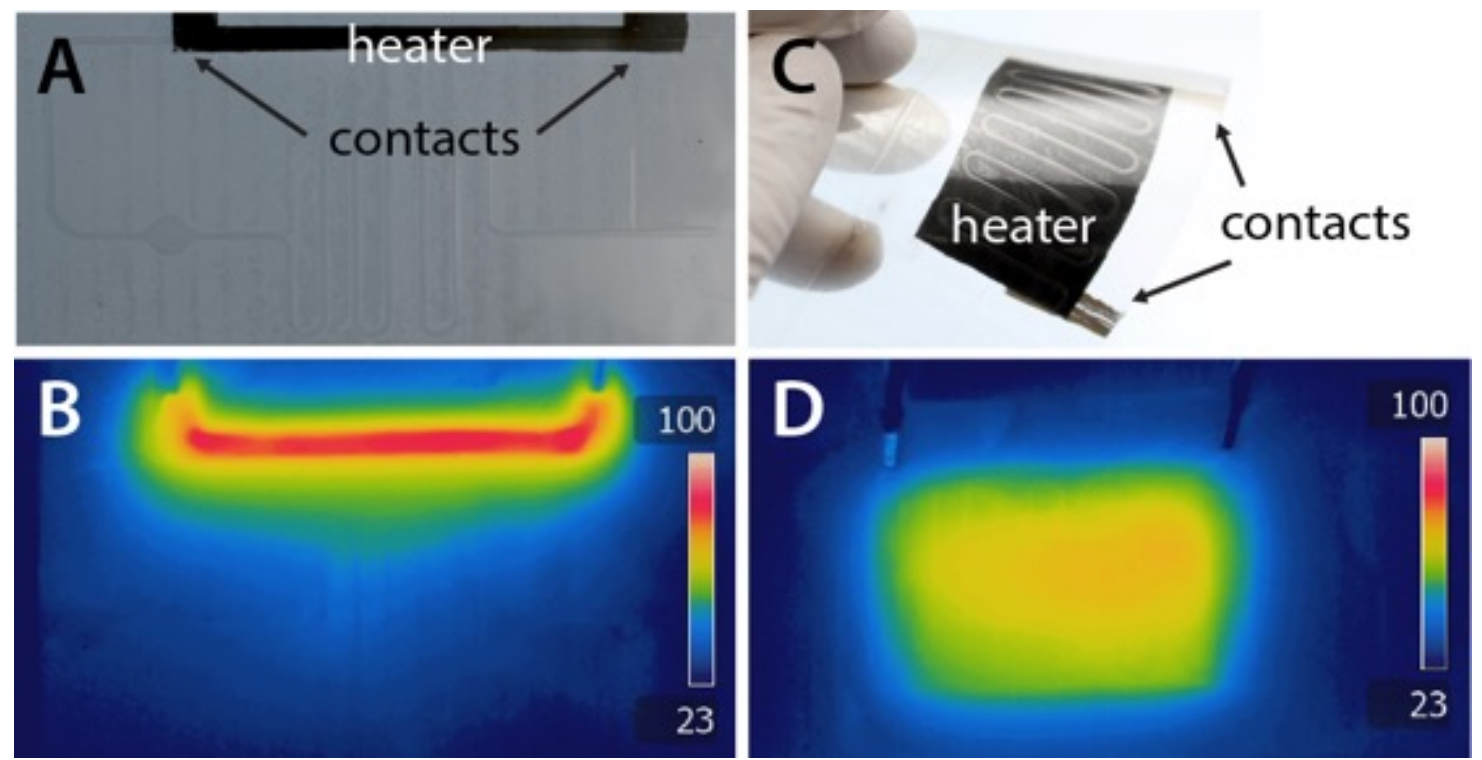

Figure 8 (A,C) Photographs of a carbon electrodes printed on the backside of PVCcoated cellophane $\left(\mathrm{C}^{\mathrm{PVC}}\right)$ microfluidic devices to act as resistive heaters. A) The heater is printed along a single channel. C) The heater is printed on the entire area of serpentine channels. B, D) Infrared images from the heaters in A) and C) during operation. Both heaters operated using a power input of around $1 \mathrm{~W}$. The temperature is given in Celsius. 


\section{REFERENCES}

(1) Yetisen, A. K.; Akram, M. S.; Lowe, C. R. Paper-Based Microfluidic Point-ofCare Diagnostic Devices. Lab Chip 2013, 13, 2210-2251.

(2) Martinez, A. W.; Phillips, S. T.; Whitesides, G. M. Diagnostics for the Developing World: Microfluidic Paper-Based Analytical Devices. Anal. Chem. 2010, $82,3-10$.

(3) Adkins, J.; Boehle, K.; Henry, C. Electrochemical Paper-Based Microfluidic Devices. Electrophoresis 2015, 36, 1811-1824.

(4) Cate, D. M.; Adkins, J. A.; Mettakoonpitak, J.; Henry, C. S. Recent Developments in Paper-Based Microfluidic Devices. Anal. Chem. 2015, 87, $19-41$.

(5) Maxwell, E. J.; Mazzeo, A. D.; Whitesides, G. M. Paper-Based Electroanalytical Devices for Accessible Diagnostic Testing. MRS Bull. 2013, $38,309-314$.

(6) Martinez, A. W.; Phillips, S. T.; Whitesides, G. M. Three-Dimensional Microfluidic Devices Fabricated in Layered Paper and Tape. Proc. Natl. Acad. Sci. U. S. A. 2008, 105, 19606-19611.

(7) Hamedi, M. M.; Ainla, A.; Güder, F.; Christodouleas, D. C.; FernándezAbedul, M. T.; Whitesides, G. M. Integrating Electronics and Microfluidics on Paper. Adv. Mater. 2016, 28, 5054-5063.

(8) Götze, K. Chemiefasern Nach Dem Viskoseverfahren; Springer Berlin Heidelberg, 1967.

(9) Klemm, D.; Heublein, B.; Fink, H. P.; Bohn, A. Cellulose: Fascinating 
Biopolymer and Sustainable Raw Material. Angew. Chem. Int. Ed. Engl. 2005, $44,3358-3393$.

(10) Mourad, A. L.; Silva, H. L. G.; Nogueira, J. C. B. Life Cycle Assessment of Cellulose Packaging Materials Production: Folding Box Board and Kraftliner Paper. Int. J. Life Cycle Assess. 2014, 19, 968-976.

(11) Sirvio, J. A.; Liimatainen, H.; Niinimaki, J.; Hormi, O. Sustainable Packaging Materials Based on Wood Cellulose. RSC Adv. 2013, 3, 16590-16596.

(12) Miyamoto, T.; Takahashi, S.; Ito, H.; Inagaki, H.; Noishiki, Y. Tissue Biocompatibility of Cellulose and Its Derivatives. J. Biomed. Mater. Res. 1989, $23,125-133$.

(13) Zhang, L.; Liu, H. Biodegradability of Regenerated Cellulose Films in Soil. Ind. Eng. Chem. Res. 1996, 35, 4682-4685.

(14) Bochek, A. M. Effect of Hydrogen Bonding on Cellulose Solubility in Aqueous and Nonaqueous Solvents. Russ. J. Appl. Chem. Zhurnal Prikl. Khimii Orig. Russ. Text 2003, 76, 1711-1719.

(15) Sen, S.; Martin, J. D.; Argyropoulos, D. S. Review of Cellulose NonDerivatizing Solvent Interactions with Emphasis on Activity in Inorganic Molten Salt Hydrates. ACS Sustain. Chem. Eng. 2013, 1, 858-870.

(16) Zhang, B.; Azuma, J.; Uyama, H. Preparation and Characterization of a Transparent Amorphous Cellulose Film. RSC Adv. 2015, 5, 2900-2907.

(17) Yetisen, A. K.; Akram, M. S.; Lowe, C. R. Paper-Based Microfluidic Point-ofCare Diagnostic Devices. Lab Chip 2013, 13, 2210-2251.

(18) Carrilho, E.; Martinez, A. W.; Whitesides, G. M. Understanding Wax Printing: A Simple Micropatterning Process for Paper-Based Microfluidics. Anal. Chem. 
2009, 81, 7091-7095.

(19) Lan, W.-J.; Maxwell, E. J.; Parolo, C.; Bwambok, D. K.; Subramaniam, A. B.; Whitesides, G. M. Paper-Based Electroanalytical Devices with an Integrated, Stable Reference Electrode. Lab Chip 2013, 13, 4103-4108.

(20) Sharma, H.; Nguyen, D.; Chen, A.; Lew, V.; Khine, M. Unconventional LowCost Fabrication and Patterning Techniques for Point of Care Diagnostics. Ann. Biomed. Eng. 2011, 39, 1313-1327.

(21) Glavan, A. C.; Martinez, R. V; Maxwell, E. J.; Subramaniam, A. B.; Nunes, R. M. D.; Soh, S.; Whitesides, G. M. Rapid Fabrication of Pressure-Driven OpenChannel Microfluidic Devices in Omniphobic R(F) Paper. Lab Chip 2013, 13, 2922-2930.

(22) Thuo, M. M.; Martinez, R. V.; Lan, W. J.; Liu, X.; Barber, J.; Atkinson, M. B. J.; Bandarage, D.; Bloch, J. F.; Whitesides, G. M. Fabrication of Low-Cost Paper-Based Microfluidic Devices by Embossing or Cut-and-Stack Methods. Chem. Mater. 2014, 26, 4230-4237.

(23) Renault, C.; Anderson, M. J.; Crooks, R. M. Electrochemistry in HollowChannel Paper Analytical Devices. J. Am. Chem. Soc. 2014, 136, 4616-4623.

(24) Renault, C.; Li, X.; Fosdick, S. E.; Crooks, R. M. Hollow-Channel Paper Analytical Devices. Anal. Chem. 2013, 85, 7976-7979.

(25) Tabeling, P. Introduction to Microfluidics; Oxford University Press, 2010.

(26) Ellerbee, A. K.; Phillips, S. T.; Siegel, A. C.; Mirica, K. a.; Martinez, A. W.; Striehl, P.; Jain, N.; Prentiss, M.; Whitesides, G. M. Quantifying Colorimetric Assays in Paper-Based Microfluidic Devices by Measuring the Transmission of Light through Paper. Anal. Chem. 2009, 81, 8447-8452. 
(27) Innovia films http://www.innoviafilms.com.

(28) Glavan, A. C.; Martinez, R. V.; Subramaniam, A. B.; Yoon, H. J.; Nunes, R. M. D.; Lange, H.; Thuo, M. M.; Whitesides, G. M. Omniphobic "RF Paper" produced by Silanization of Paper with Fluoroalkyltrichlorosilanes. Adv. Funct. Mater. 2014, 24, 60-70.

(29) Piruska, A.; Nikcevic, I.; Lee, S. H.; Ahn, C.; Heineman, W. R.; Limbach, P. a; Seliskar, C. J. The Autofluorescence of Plastic Materials and Chips Measured under Laser Irradiation. Lab Chip 2005, 5, 1348-1354.

(30) Badu-Tawiah, A. K.; Lathwal, S.; Kaastrup, K.; Al-Sayah, M.; Christodouleas, D. C.; Smith, B. S.; Whitesides, G. M.; Sikes, H. D. Polymerization-Based Signal Amplification for Paper-Based Immunoassays. Lab Chip 2015, 15, 655659.

(31) Glavan, A. C.; Niu, J.; Chen, Z.; Güder, F.; Cheng, C. M.; Liu, D.; Whitesides, G. M. Analytical Devices Based on Direct Synthesis of DNA on Paper. Anal. Chem. 2016, 88, 725-731.

(32) López-de-Alba, P. L.; López-Martínez, L.; Cerdá, V.; Amador-Hernández, J. Simultaneous Determination and Classification of Riboflavin, Thiamine, Nicotinamide and Pyridoxine in Pharmaceutical Formulations, by UV-Visible Spectrophotometry and Multivariate Analysis. J. Braz. Chem. Soc. 2006, 17, $715-722$.

(33) Sirajuddin; Khaskheli, A. R.; Shah, A.; Bhanger, M. I.; Niaz, A.; Mahesar, S. Simpler Spectrophotometric Assay of Paracetamol in Tablets and Urine Samples. Spectrochim. Acta - Part A Mol. Biomol. Spectrosc. 2007, 68, 747751. 
(34) Lee, C.-Y.; Chang, C.-L.; Wang, Y.-N.; Fu, L.-M. Microfluidic Mixing: A Review. Int. J. Mol. Sci. 2011, 12, 3263-3287.

(35) White, F. M. Viscous Fluid Flow; McGraw-Hill, 1991.

(36) Pardee, K.; Green, A. A.; Ferrante, T.; Cameron, D. E.; DaleyKeyser, A.; Yin, P.; Collins, J. J. Paper-Based Synthetic Gene Networks. Cell 2014, 159, 940954.

(37) Holstein, C. A.; Chevalier, A.; Bennett, S.; Anderson, C. E.; Keniston, K.; Olsen, C.; Li, B.; Bales, B.; Moore, D. R.; Fu, E.; et al. Immobilizing Affinity Proteins to Nitrocellulose: A Toolbox for Paper-Based Assay Developers. Anal. Bioanal. Chem. 2016, 408, 1335-1346.

(38) Rackus, D. G.; Shamsi, M. H.; Wheeler, A. R. Electrochemistry, Biosensors and Microfluidics: A Convergence of Fields. Chem. Soc. Rev. 2015, 44, 53205340.

(39) Scampicchio, M.; Wang, J.; Mannino, S.; Chatrathi, M. P. Microchip Capillary Electrophoresis with Amperometric Detection for Rapid Separation and Detection of Phenolic Acids. J. Chromatogr. A 2004, 1049, 189-194.

(40) Suea-Ngam, A.; Rattanarat, P.; Chailapakul, O.; Srisa-Art, M. Electrochemical Droplet-Based Microfluidics Using Chip-Based Carbon Paste Electrodes for High-Throughput Analysis in Pharmaceutical Applications. Anal. Chim. Acta 2014, $883,45-54$.

(41) Hunter, R. A.; J. Privett, B.; Henley, W. H.; Breed, E. R.; Liang, Z.; Mittal, R.; Yoseph, B. P.; E. McDunn, J.; Burd, E. M.; Coopersmith, C. M.; et al. Microfluidic Amperometric Sensor for Analysis of Nitric Oxide in Whole Blood. Anal. Chem. 2013, 85, 6066-6072. 
(42) Chikkaveeraiaha, B. V.; Liu, H.; Vigneshwaran, M.; Papadimitrakopoulos, F.; Rusling, J. F. A Microfluidic Electrochemical Device for High Sensitivity Biosensing: Detection of Nanomolar Hydrogen Peroxide. Electrochem.

Commun. 2009, 11, 819-822.

(43) Roche Holding AG http://www.cobas.com/home/product/clinical-andimmunochemistry-testing/technology-elecsys-ecl.html.

(44) Delaney, J. L.; Doeven, E. H.; Harsant, A. J.; Hogan, C. F. Use of a Mobile Phone for Potentiostatic Control with Low Cost Paper-Based Microfluidic Sensors. Anal. Chim. Acta 2013, 790, 56-60.

(45) Shin, I.-S.; Kang, Y.-T.; Lee, J.-K.; Kim, H.; Kim, T. H.; Kim, J. S. Evaluation of Electrogenerated Chemiluminescence from a Neutral Ir(III) Complex for Quantitative Analysis in Flowing Streams. Analyst 2011, 136, 2151-2155.

(46) Leet, W.; Nieman, T. A. Evaluation of Use of Tris(2,2'bipyridyl)ruthenium(Ill) as a Chemiluminescent Reagent for Quantitation in Flowing Streams. Anal. Chem. 1995, 67, 1789-1796.

(47) Miao, W.; Choi, J. P. Electrogenerated Chemiluminescence; Bard, A. J., Ed.; Marcel Dekker Inc., 2004.

(48) Wang, Q.; Lin, X.; Guo, D.; Xu, J.; Xuan, C.; Chen, C.; Fu, Y. A Novel Chiral Electrochemiluminescence Sensor That Can Discriminate Proline Enantiomers. RSC Adv. 2015, 5, 94338-94343.

(49) Miao, W.; Bard, A. J. Electrogenerated Chemiluminescence. 72. Determination of Immobilized DNA and C-Reactive Protein on Au(111) Electrodes Using Tris(2,2 -bipyridyl)ruthenium(II) Labels. Anal. Chem. 2003, 75, 5825-5834.

(50) Khan, M. S.; Thouas, G.; Shen, W.; Whyte, G.; Garnier, G. Paper Diagnostic 
for Instantaneous Blood Typing. Anal. Chem. 2010, 82, 4158-4164.

(51) Klemm, D.; Kramer, F.; Moritz, S.; Lindström, T.; Ankerfors, M.; Gray, D.; Dorris, A. Nanocelluloses: A New Family of Nature-Based Materials. Angew. Chem. Int. Ed. Engl. 2011, 50, 5438-5466.

(52) Plackett, D.; Hedenqvist, M.; Ankerfors, M.; Lindström, T. Highly Transparent Films from Carboxymethylated Microfibrillated Cellulose : The Effect of Multiple Homogenization Steps on Key Properties. J. Appl. Polym. Sci. 2011, $119,2652-2660$.

(53) Goodfellow Corporation http://www.goodfellow.com/E/CellulosePolymer.html (accessed Mar 31, 2016).

(54) Ellis Bryan, S. R. Polymers: A Property Database, Second Edition Bryan Ellis, Ray Smith; Taylor \& Francis Group LLC, 2008.

(55) Kinyua, D. M.; Rurimo, G. K.; Karimi, P. M.; Maina, S. N.; Ominde, C. F. Interferometry Analysis of Cellophane Birefringence. Opt. Photonics J. 2013, $3,337-341$. 